\title{
Investigation the Performance of Cross Flow Heat Exchanger
}

\author{
Dr. Sadiq Elias Abdullah \\ Department of Production Engineering \& Metallurgy, Technical College of Engineering, Sulaimani Polytechnic University, \\ Kurdistan region-Iraq.
}

\begin{abstract}
In this study the performance of cross flow heat exchanger staggered tube bank arrengment are experimentally investigated. Four sets of tube bank consisting of 24 tubes, six rows each four tubes, are used for all experiments. Creating a number of (14, 29, 59) $V$-grove shape of one $\mathrm{mm}$ depth on outer surface of three sets while the fourth remain as it is smooth. Reynolds number based on maximum velocity in tube banks varied from (1380) to (51380) while heat flux supplied from ( 10 ) to (120) W/m $\mathrm{m}^{2}$ by steps of 10 's varied. The heat transfer results of a smooth tube bank tests matches with other researchers are in good agreement. Meanwhile, other sets shows that the heat transfer increase with increases of Reynolds number, while non dimensional pressure drop decrease with increases of Reynolds number. A new Nusselt number-Reynolds number correlation was found.
\end{abstract}

Keywords: Cross flow heat exchanger, staggered tube bank, grove,heat transfer,presure drop.

\section{Nomenclature}

\begin{tabular}{|c|c|c|}
\hline $\mathrm{A}$ & Surface area of element & $\mathrm{m}^{2}$ \\
\hline $\mathrm{d}$ & Diameter of element & $\mathrm{mm}$ \\
\hline $\mathrm{h}$ & Heat transfer coefficient, & $\mathrm{W} / \mathrm{m}^{2} . \mathrm{K}$ \\
\hline $\mathrm{k}$ & Thermal Conductivity of air & $\mathrm{W} / \mathrm{m} . \mathrm{K}$ \\
\hline $\mathrm{L}$ & Effective length of element & $\mathrm{m}$ \\
\hline $\mathrm{Nu}$ & Nusselt Number ( hL $/ \mathrm{k})$ & \\
\hline $\mathrm{Re}_{\max }$ & Reynolds number $\left(\mathrm{V}_{\max } \mathrm{L} \rho / \mu\right)$ & \\
\hline $\mathrm{S}_{\mathrm{l}}$ & longitude pitch of tube bank & $\mathrm{mm}$ \\
\hline $\mathrm{S}_{\mathrm{t}}$ & Transvers pitch of tube bank & $\mathrm{mm}$ \\
\hline $\mathrm{T}_{\mathrm{a}}$ & Temperature of air & $\mathrm{K}$ \\
\hline $\mathrm{T}_{\mathrm{f}}$ & Temperature of air film & $\mathrm{K}$ \\
\hline $\mathrm{T}_{\mathrm{h}}$ & Temperature of surface element & $\mathrm{K}$ \\
\hline $\mathrm{V}$ & inlet velocity into duct & $\mathrm{m} / \mathrm{s}$ \\
\hline $\mathrm{V}_{\max }$ & Maximum velocity passes tube bank & $\mathrm{m} / \mathrm{s}$ \\
\hline$\rho$ & Density of air & $\mathrm{kg} / \mathrm{m}^{3}$ \\
\hline$\mu$ & Viscosity of air & $\mathrm{kg} \cdot \mathrm{s} / \mathrm{m}^{2}$ \\
\hline$\Delta \mathrm{P}$ & Pressure difference & $\mathrm{Pa}$ \\
\hline$\Delta \mathrm{P}^{*}$ & Non dimensional Pressure difference & \\
\hline
\end{tabular}

\section{Introduction}

Cross flow heat exchanger are found in different industrial sectors,such as steam generation in a boiler or air cooling in the coil of an air conditioner, where heat has transferred between different media. For optimal design of heat exchanger and flow pattern, the determination of its operational parameters and performance. The pressure drop and heat transfer between the fluid flow and the structure have to be known. one of methods to determine the performance is experimental work . Fahmy and Mohamed [1] investigited the characterstic of atube bank when some simple extented surface of different geometeries (simple fin in down stream end, simple fin in both up strem and down stream end, and $v$ shaped fin down strem) the investigation has been carried out in two plases,in-line and stagered arrangement .lowest value of $\mathrm{Nu} / \Delta \mathrm{P}^{*}$ have been obtained for $\mathrm{V}$ shaped finned tube in theire in line and staggered arrangment of other hand in line arrangement of plaine circular tube has resul of high $\mathrm{Nu} / \Delta \mathrm{P}^{*}$ at low Re max however this ratio decresed as Re max incresed, They result showed that single sided straight fin (fixed at the back of tube) will be advantagesose. Sperrow ( as reported in [1] )performed heat transfer and pressure drop experiment for cross flow tube bank in which the individual tube were equipped with longitudinal fins in this experments ,they investigated the effect of fin tip geometery (blunt and contoured) and fin configuration or plaement (at the rear,at the front, and atboth rear and front) ,the experment was performed for reynolds number range from 1000-8600 ,the results indicated that the high degree of heat transfer enhancement can be obtained by finning, comparing the results of the finned tubes to those of increeased diamter unfinned tube showed that finning yields significantly greater heat transfer enhancement for the same pressure drop. Edwaed[2] performed experiment consisted of measurment of pressure losses and heat transfer rate for two unconventional cross flow heat exchanger.the first type consisted of an arrangement of circularr tube in a sawtooth patteren.perfomance of this type did not appear to be improvement over more conventional heat exchanger,while the second type used exchanger tube of a speical lenticular cross section.so spaced as to keep the velocity of the fluid flowing out side the tube nearly constant in magnitude reducing seperation and drage. The lenticular tubes perfomance was superior to conventional type,especially at high reynolds number. Sundus H. Abd[3] Experimental study was made on free and forced heat transfer from three cylinders of different cross-sections circular, triangular and square in cross flow of air. The three cylinders were manufactured from copper for its high conductivity. The three cylinders were made to have equal surface area to compare the effect of their shape on heat transfer coefficient. It was found that in the case of forced convection, the heat transfer of the triangular cylinder is better than that of the square and circular cylinder and several empirical relationships were obtained for the case of forced convection. Igbinosa and Christian [4]They found in numerical and experimental investigations that changes in heat transfer from copper tube was dependent on the position and flow pattern (Reynolds number) in the heat exchanger while the pressure drop was a function of the Reynolds numbers.The heat transfer coefficient from the heated element was found to be a function of its position and 


\section{International Journal of Science and Research (IJSR) \\ ISSN (Online): 2319-7064 \\ Index Copernicus Value (2013): 6.14 | Impact Factor (2015): 6.391}

Reynolds number in the tube bank. Nusselt number increase by $12.49 \%$ from first to second column, $11.85 \%$ from second to third column and $5.27 \%$ from third to fourth column. This was due to increasing level of turbulence created by successive column of tubes as the air passes through the bank. However, the increments were at diminishing rate in successive column of tubes. Downstream from the third column, the heat transfer stabilizes, such that little change occurs in the convection coefficient from tube beyond the fourth. Tahseen A.Tahseen,et.,al.[5] In this study, an experimental study of heat transfer and air flow over in-line flat tube bundle. They found the average Nusselt number of air flow increases with the increase of Reynolds number . In present study effect of v-grove in $1 \mathrm{~mm}$ dpth which made on the surface tube bank with different number grove (14,29, and 59) ,tube bank are arrangged in staggered ,in this study heat transfer and pressure drop are investigted.idea of small groved on surface of tube bank is simulation to finite ribes on the skin of fish and dolphen which reduce friction with water.

\section{Equipment and Test Samples}

The test rig is coposed of adraw-through wind tunel having a square cross section of $(15 * 15) \mathrm{cm}$ being set horizontally. The main part of the rig is the working section with spaces provided for the tube as shown in Figure 1 . One of the spaces is occupied by element consisting of tube of pure copper approximately of $15 \mathrm{~cm}$ long carried between two extension rods of a fabric-based plasic compound. The element is heated by electric heater bulit in. The heating element temperature is indicated by thermocouple type $\mathrm{K}$ which embieded in surface. The geometric layout of tube bank is staggered with four rows of six tubes. The tube diamter transverese pitch and horizontal pitch are $13 \mathrm{~mm}, 23$ $\mathrm{mm}$ and $20 \mathrm{~mm}$ respectivity.

The apparatus includs a centrifugal fan drivn by1200W electric motor and having its inlet connected to the working section. Air enters the test section by way of bell-mouth, aftere working section, a transition piece lead to the fan inlet and carries a honcycomb flous straightener intended to prevent the transmission of swiral from the fan back into the working section.the fan discharge regulated by flab which regulated air velocity through appartus. Associated static tapping are provided so that the pressure drop across tube bundle are measured,for this purpose the inclined tube manometer is connected to the bottom measuringduct.the total pressure is measured with aid of pitot tube,to determine the flow velocity,the dynamic pressure is determine by inclined manometer,which one side connected to pitot tube "total pressure" and other side connected to tapping "static pressure",the difference is dynamic pressure ,which used to calculated velocity of air flow. Present study invtigated the prformance of a tube bank when the surface of tubes are groved with different number v-grove with depth of $1 \mathrm{~mm}$ as shown in Figure 2.

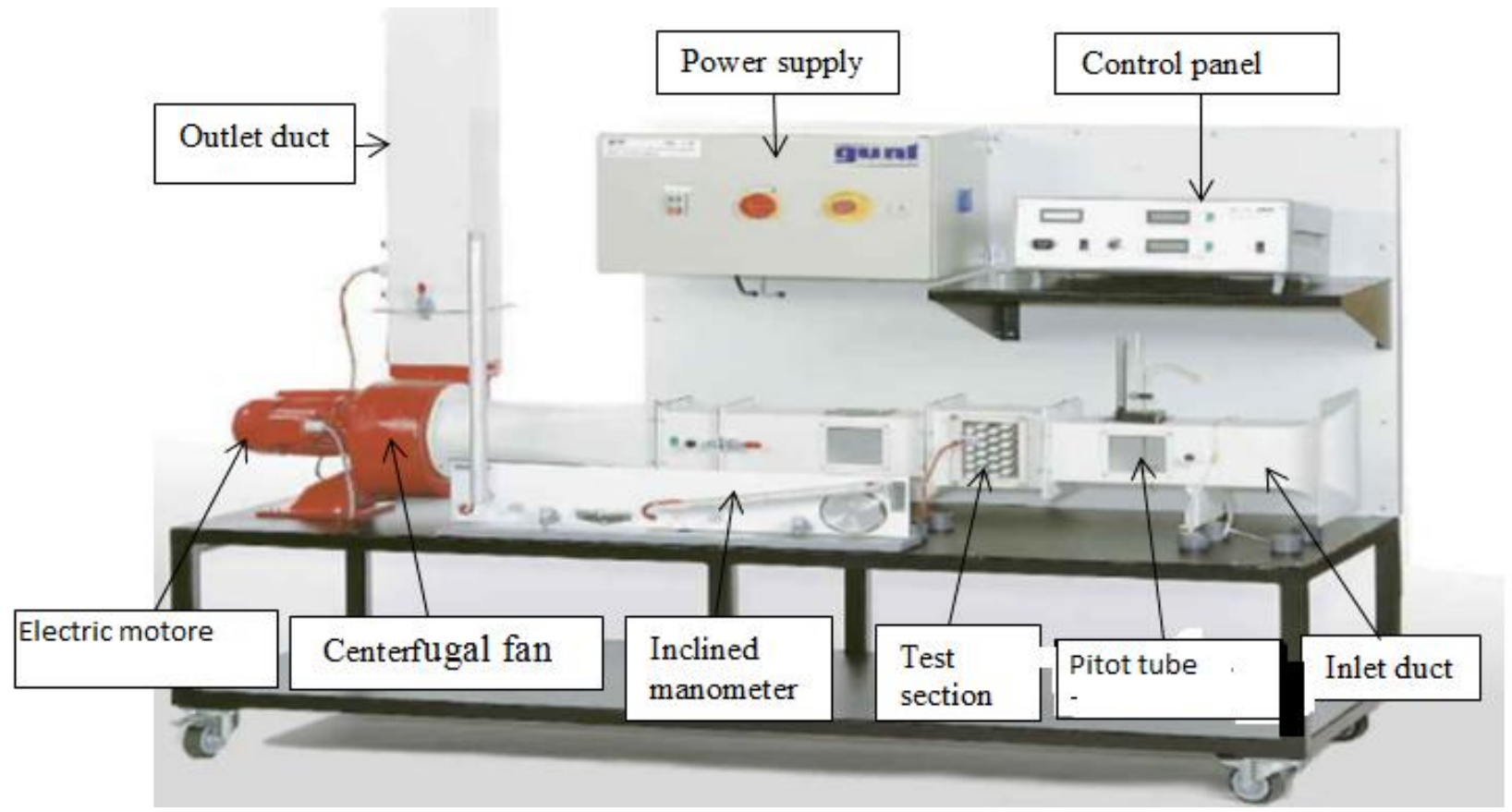

Figure 1: Apparature used in test 


\section{International Journal of Science and Research (IJSR) \\ ISSN (Online): 2319-7064}

Index Copernicus Value (2013): 6.14 | Impact Factor (2015): 6.391
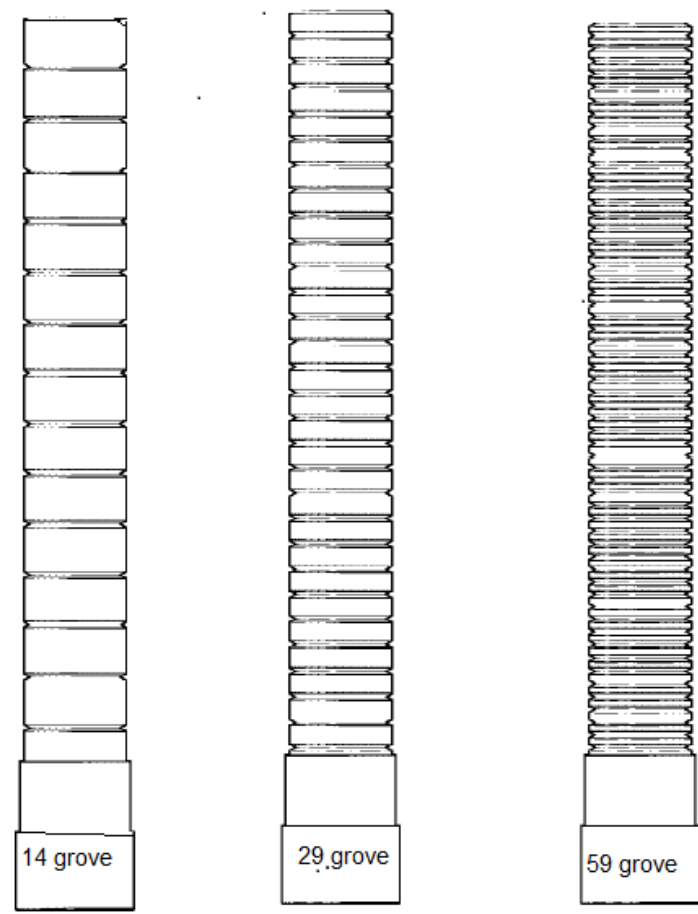

Figure 2: The sampels are used in present study with number of grvoe for each case

The expermental data were used to determine Reynolds number $(R e)_{\max }$ for flow over tube based on the minimum area avavilable for fluid flow in staggared arrangement and charastristic length of flow, Incropera [6], Buyruk[7]

And

$$
(R e)_{\max }=\frac{\mathrm{p} \mathrm{V}_{\max } L}{\mu}
$$

$$
\mathrm{Vmax} \mid=\left(\frac{S l-S t}{d}\right) V
$$

Where:

$\mathrm{V}_{\max }=$ maximum velocity of flow for staggered arrangment according the following Incropera.

$S_{l}=$ longtidual pitch of tube bank ( $\left.23 \mathrm{~mm}\right)$.

$S_{t}=$ tranvers pitch of tube bank ( $\left.20 \mathrm{~mm}\right)$.

$V=$ inlet velocity $(\mathrm{m} / \mathrm{sec})$.

$d=$ diamter of tube $(13 \mathrm{~mm})$, and

$L=$ is path of flow over tube $=(\pi d / 2)$.

The properties of fluid is calculated based on the film air temperature.

$\mathrm{T}_{\mathrm{f}}=\left(\mathrm{T}_{\mathrm{h}}+\mathrm{T}_{\mathrm{a}}\right) / 2$

The convection heat transfer coefficient h was calculated using newtons law of cooling.

$$
Q=h A\left(T_{h}-T_{a}\right)
$$

Where:

$A=$ surface area of heating element.

$T_{h}=$ surface temperature of heating element.

$T_{a}=$ temperture of air at duct inlet.

$Q=$ steady state power input to appartuse.

Power input to heating element. this power disspateded in two mechancems convection and radiation, for the range of temperature difference during tests, heat transfer by radiation for maximum not more than $3 \%$, according to this ratio heat transfer by radiation neglected,assume heat tranfer only by convection.

Nusselt number was calculated for each run as:

$$
\text { Nu. No. }=\frac{h L}{k}
$$

Where:

$k$ : Is the thermal conductivity of air at film temperature $T_{f}$

Pressure drop was measured between two taps across tube bundle. Pressure drop has nondimensionalizes by manes of following equation, Incropera [6 ], Buyruk [7].

$$
\Delta \mathrm{P}^{*}=\frac{\Delta P}{0.5 \rho V}
$$

\section{Results and Discussion}

Firstly the heat transfer results, as shown in Figure 3, for smooth surface tube of the geomtery arrangmenmt $(\mathrm{St} / \mathrm{d}=1.77)$ and $(\mathrm{Sl} / \mathrm{d}=1.54)$ is found as (index) 0.566 compered (index) 0.568 in ref.[6] which means agood agreement ,also, Figure 3 shown, the constant value of 0.564 found to be as higher as 0.429 taken from ref. [6], this difference due to the geomtery arrangmenmt $(\mathrm{St} / \mathrm{d}=2)$ and $(\mathrm{Sl} / \mathrm{d}=1.5)$ which means that the arrangment is more compact and suitable for higher heat transfer.

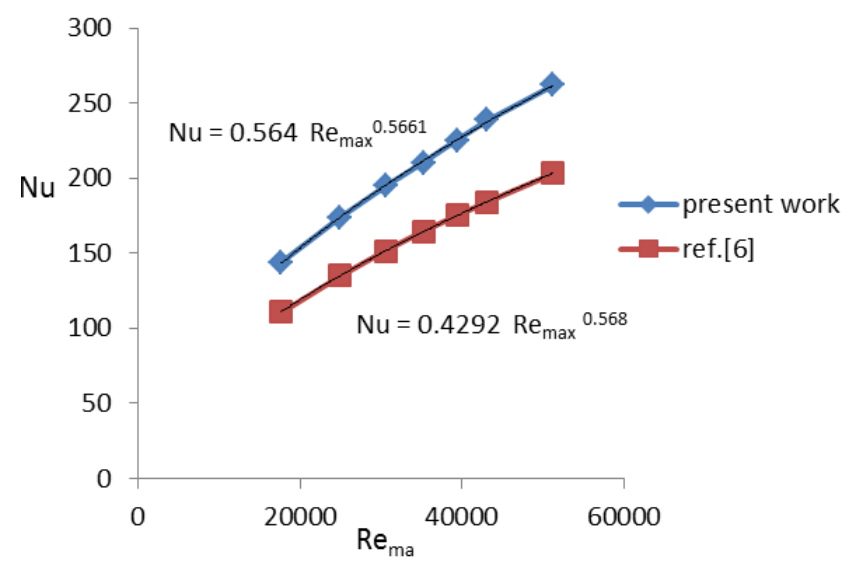

Figure 3: Present Results compered with ref. [6].

Secondly as shown in Figures 4,5 and 6 the results of heat transfer for different grooves tube sets of 14, 29 and 59, that gives different $\mathrm{Re}_{\text {max }}$ indexs as $0.54,0.426$ and 0.55 respectivily.

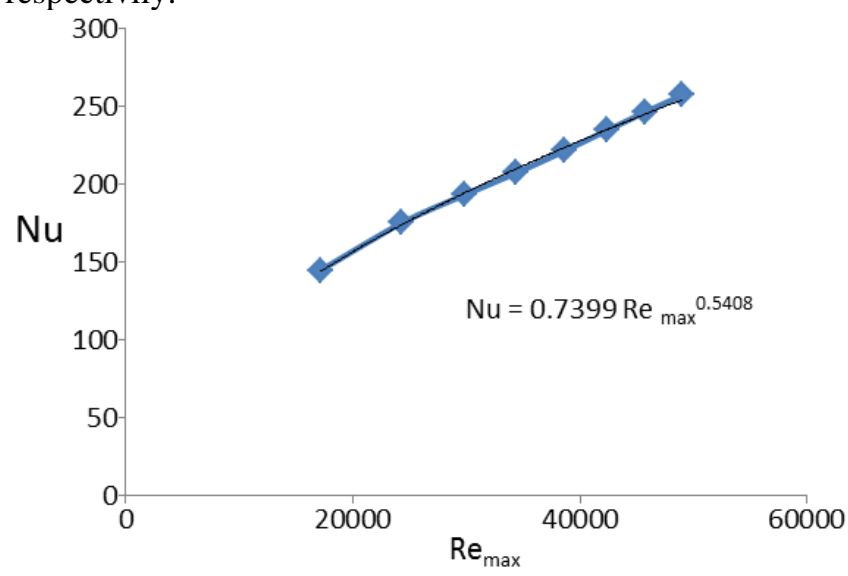

Figure 4: Nu.No. vs $\mathrm{Re}_{\max }$ for number of 14 grove. 


\section{International Journal of Science and Research (IJSR) \\ ISSN (Online): 2319-7064}

Index Copernicus Value (2013): 6.14 | Impact Factor (2015): 6.391

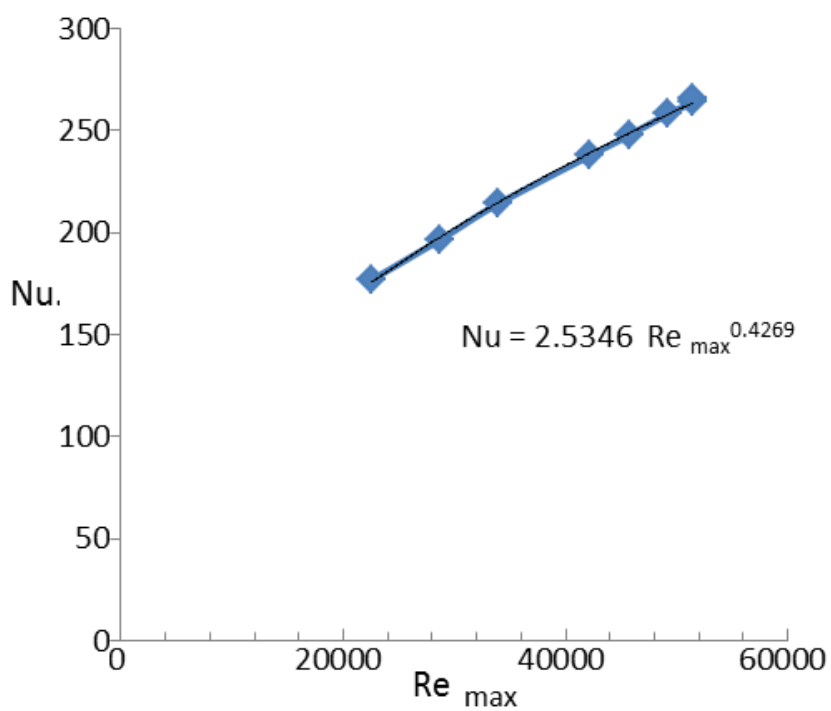

Figure 4: Nu.No vs $\mathrm{Re}_{\max }$ for number of 29 grove.

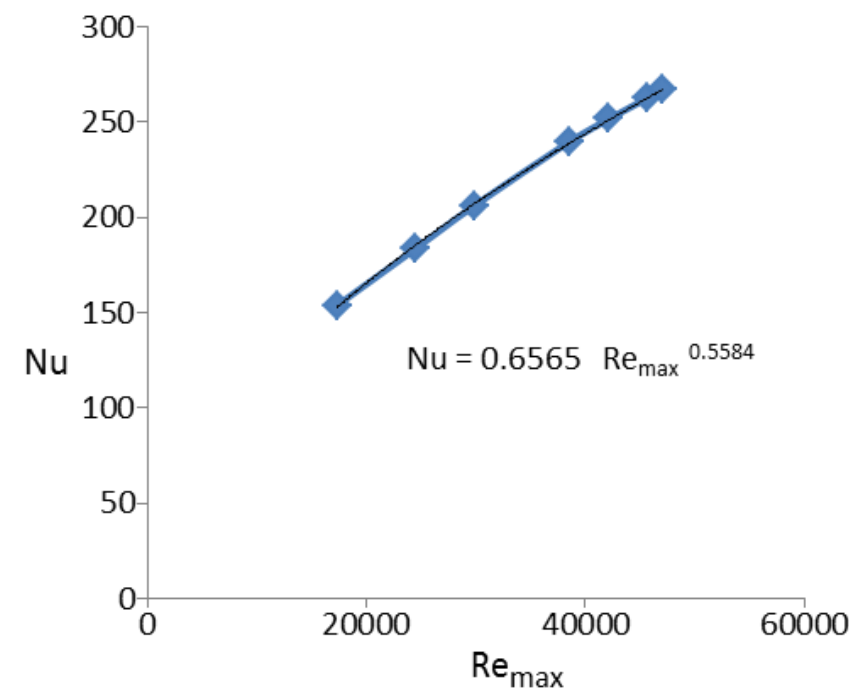

Figure 5: Nu. No vs $\mathrm{Re}_{\max }$ for 59 grove.

For more detail, Figure 6 is a collection for three sets of grooves which indicats that heat transfer better for set of 59 grooves. This is due to the flow becomes more turbelents and as a sequence this leads to higher heat transfer.

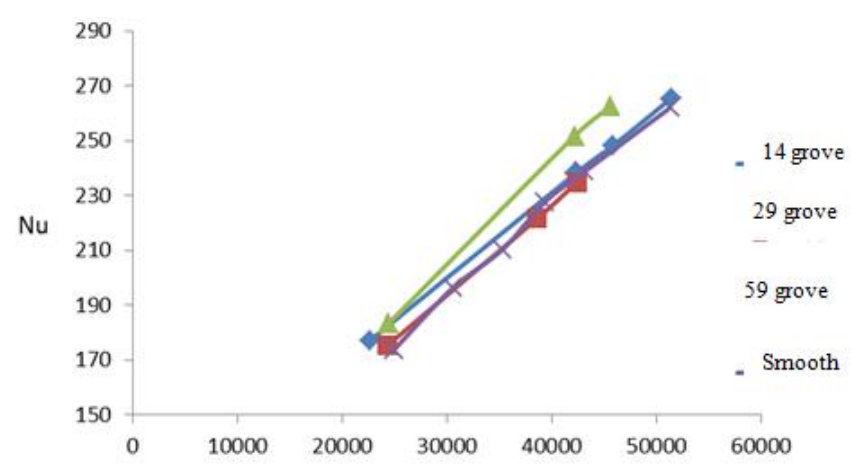

Figure 6: Comparresion heat transfer for different cases

Another important factore for selection of heat exchanger is pressure drop, nondimensional pressure drop with Reynolds number for different cases are drwen in Figure 7. which indicated that nondimensional presure drop of smooth tube bank is lower than other cases, since its lower value means minumum power consumpation, also with the increse
Reynols number decreaseing nondimensional presure drop,this due to incerse air speed across tube bank .

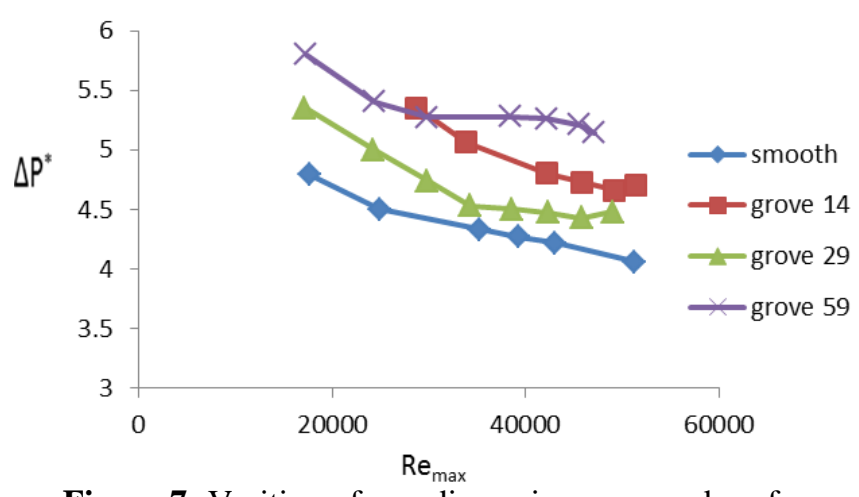

Figure 7: Varition of non dimension presure drop for different cases

\section{Conclusion}

Heat transfer and presure drop in cross flow heat exchanger experimentaly investigated, different number of groves $(14,29$ and 59) created on the outerdiameter of tube bank. It can summerised As folows:

1) Heat transfer incresed as Renolds number increases for all investigated cases.

2) Pressure drop decresed as Renolds number increase for all investigated cases.

3) For the sets of case groves 14 and 29 heat transfer higer than smooth at low Renolds number, but at higher Renolds number had same heat transfer approximatly.

4) For grove number 59 the heat transfer found to be higher than the smooth tube about $8 \%$ for all range of Reynolds number investgated.

5) For all cases non dimensional presure droop increses compered with smooth tube, and that mean more power concumption.

\section{References}

[1] Fahmy M. Hussein and Mohamed S. ElShobokshy,"Experimental Investigation of the Effect of Extended Surfaces on the Performance of Tube Banks in Cross Flow", J. King Saud Univ., Vo.l, Eng.Sci (1, 2), pp. 213-228, Riyadh (1409/1989)

[2] Edward Kenneth Ruth," Experiments with Unconventional Cross flow Heat Exchangers", Thesis for the Degree of Doctor of Philosophy Submitted To California Institute Of Technology Pasadena, California, 1981

[3] Sundus Hussein Abd, "Experimental Study on the Impact of External Geometrical Shape on Free and Forced Convection Time Dependent Average Heat Transfer Coefficient during Cooling Process", Al-Khwarizmi Engineering Journal, Vol. 8, No.3, PP 74 - 89 (2012) Chemical Engineering, 25(1) (1985), pp. 1-15.

[4] Igbinosa Ikpotokin, Christian Okechukwu Osueke," Heat Transfer and Fluid Flow Characteristics Study for InLine Tube Bank in Cross-Flow “, International Journal of Mechanical \& Mechatronics Engineering IJMME-IJENS Vol: 14 No: 03

[5] Tahseen Ahmad Tahseen, M. Ishak and M. M. Rahman,” An Experimental Study Air Flow and Heat Transfer Of 


\section{International Journal of Science and Research (IJSR) \\ ISSN (Online): 2319-7064}

Index Copernicus Value (2013): 6.14 | Impact Factor (2015): 6.391

Air Over In-Line Flat Tube Bank,", International Conference on Mechanical Engineering Research (ICMER2013), 1-3 July 2013 Bukit Gambang Resort City, Kuantan, Pahang, Malaysia Organized by Faculty of Mechanical Engineering, University Malaysia Pahang Paper ID: P040 1

[6] Incropera / DeWitt / Bergman / Lavine, "Introduction to heat Transfer", FIFTH EDITION, JOHN WILEY \&SONS INC.

[7] Ertan BUYRUK," Heat Transfer and Flow Structures Around Circular Cylinders in Cross-Flow", Tr. J. of Engineering and Environmental Science,23 (1999) , (299 $-315)$. 